\title{
Space Age: Past, Present and Possible Futures
}

\author{
José Bezerra Pessoa Filho ${ }^{1, *}$ [D
}

1.Departamento de Ciência e Tecnologia Aeroespacial - Instituto de Aeronáutica e Espaço - Divisão de Sistemas Espaciais - São José dos Campos/SP - Brazil.

*Retired; Corresponding author: jbpfilho@yahoo.com.br

\begin{abstract}
Since Gagarin's flight on April 12th, 1961, the dream of making human space flight routine and making Homo sapiens a multiplanetary species seemed to have become closer to reality. Nonetheless, on average less than 10 human flights a year have happened along the past 60 years. Unmanned spacecrafts, on the other hand, have changed the way the human race sees itself and the universe it is surrounded by. They have explored all planets in the solar system, as well as comets, asteroids and the Sun. Presently, there are four unmanned spacecrafts on Mars' surface and eight satellites in its orbit. Since the launching of Sputnik in 1957, more than 11,000 satellites have been sent into Earth's orbit. Nowadays, it is impossible to imagine life on Earth without the services provided by the space-based infrastructure resulting from the Space Age. They have changed the modus vivendi of the human civilization and become a commodity, like potable water and electricity. The so-called satellite industry generates around US $\$ 300$ billion a year, mostly related to the sale of satellite services and ground equipment. The era of exponential growth and disruption has reached Earth's orbit, and beyond, through the minds, initiatives and boldness of the NewSpace generation, from which Elon Musk is its exponent. Twenty-five thousand satellites are expected to be launched in the next 10 years to provide, among other applications, worldwide broadband internet access. The scientific community and the military, however, have already expressed their concerns regarding space debris and, as a consequence, space sustainability. For the scientific community, the long-waited launch of the James Webb Space Telescope (JWST) promises to be the 2021 main event. In a time in which Spaceship Earth faces so many challenges, the dream of making its dwellers a multiplanetary species got a revival trough the minds and actions of Elon Musk and Jeff Bezos. There are those who, through public-private partnerships, intend to establish a 1,000 people community working and living in space by 2045 . Cooperation among nations has been usual in space, but they are still shy when compared to the efforts required to colonize the Moon, Mars and other places in the solar system. As the $21^{\text {st }}$ century advances, Spaceship Earth faces its greatest challenge ever. Space-based assets provide all the tools required to monitor Earth's health, but if the human species intends to survive as the only identified intelligent civilization, it will have to think and act united in a truly cooperative way. Otherwise, the civilizational and technological effort hitherto undertaken may prove to be useless.
\end{abstract}

Keywords: Golden Rush; Space Colonization; Space debris; Defense and space; New space; Space 3.0

\section{INTRODUCTION}

In April 2021, the $60^{\text {th }}$ anniversary of Yuri Gagarin's historic space flight was celebrated. Less than two months after Gagarin's flight, the USA announced its decision to send humans to the Moon and bring them back. The impact of Neil Armstrong and Buzz Aldrin's arrival on the Moon, on July $20^{\text {th }}, 1969$, was such that von Braun predicted that manned flight to Mars would occur in the middle of the 1980s. Indeed, von Braun had always dreamed of a Mars trip (von Braun 1953). Before that, in 1975, the

Received: May 10, 2021 | Accepted: May 25, 2021

Peer Review History: Invited paper, not peer reviewed.

Section Editor: Alison Moraes

This is an open access article distributed under the terms of the Creative Commons license. 
Apollo - Soyuz manned spacecrafts carried out a historic space docking, which for many marked the end of the Cold War in space. In the 1990s, Russia gave up its Mir space station in exchange for its participation in the American initiative to build the International Space Station (ISS), in orbit since 1998. In December 2022, the $50^{\text {th }}$ anniversary of the last manned mission to the Moon will be celebrated, under the expectation that an American woman will land on the Moon by the end of this decade, within National Aeronautics and Space Administration (NASA) Artemis program. Sixty years after Gagarin's flight, sending humans to space is still the exception, not the rule, as less than 600 humans have crossed the border of space, i.e., the $100 \mathrm{~km}$ altitude defined as the Kármán line.

In addition to manned flights, the Space Age opened the era of scientific discoveries, the first of which was carried out in 1958 when an experiment aboard Explorer I confirmed the existence of Van Allen belts, named after the scientist responsible for the experiment. Since then, there have been more than 200 unmanned missions to all the planets in the solar system, including the Moon, asteroids, comets and the Sun. So far, the Hubble space telescope has been one of the most outstanding space devices ever, as it registered the birth and death of stars. And what about the more than 4,000 exoplanets discovered in this century, aided by space and terrestrial artifacts (NASA 2021a)? Right now, the lander Insight, the Curiosity and Perseverance rovers and the Ingenuity helicopter, all from NASA, are on the Martian surface looking for signs of life, past or present. Not to forget the six-wheeled Zhurong rover, which made China the second country to ever land a rover on Mars. Around the Red Planet, there are eight artificial satellites, representing the USA, India, Russia, China, United Arab Emirates and the European Space Agency (ESA). In October, an Ariane 5 rocket is scheduled to launch the US\$ 10 billion James Webb Space Telescope (JWST), which will be placed near the Earth-Sun L2 Lagrangian point beyond the Moon. The JWST is a joint effort of NASA, the ESA and the Canadian Space Agency (CSA). Besides financial resources and international collaboration, the JWST is a result of a remarkable combination of science, technology and boldness.

\section{From space 1.0 to space 2.0}

Part of the achievements presented in the preceding section occurred in the 1950s, 1960s and 1970s, as result of government initiatives, some of which had geopolitical objectives, such as the Apollo Program. Chris Quilty, from Quilty Analytics, qualifies that period as Space 1.0, but, at least in the capitalist world, the governmental resources were invested in private companies. In the Apollo Program, 85\% of NASA's resources were spent on 20,000 private companies, involving 360,000 professionals. In current values, the Apollo Program costs US\$ 283 billion (The Planetary Society 2020). In the USA, private companies have always taken part in the space effort. In the past, these companies were hired under "cost-plus" contracts, i.e., they were paid for their expenses plus a profit margin. Nowadays, the private sector is hired under "fixed-price" contracts and, in many cases, it has to share part of the development costs under the expectation it will be rewarded by selling its services to NASA and other interested clients.

Although manned flights have become the most visible part of the Space Age, it was the more than 11,000 satellites launched since Sputnik, in 1957, that changed the modus vivendi of the human civilization. The nearly 3,500 satellites in operation today are part of a space-based infrastructure providing, among others: weather and climate forecasting; communications; data transmission; remote sensing; environmental monitoring; search and rescue; global positioning systems; and object and animal tracking. In 2019, this market generated US\$ 271 billion, divided as follows: construction and launching of rockets (2\%), construction of satellites (5\%), sale of satellite services (45\%) and sale of ground equipment (48\%) (SIA 2020). On the top of that, governments and commercial human spaceflight have added US\$ 95 billion. Countries that are not capable of launching their satellites with their own rockets are deprived of exploring 93\% of the market, i.e., sale of satellite services and ground equipment. While in Space 1.0 the initiatives were all governmental, in Space 2.0 large corporations started to invest in space initiatives, whose genesis can be considered the Iridium constellation, created by Motorola at the end of the 1980 s with the goal of providing mobile satellite telephony in remote regions of the globe (Sweeting 2018).

\section{The intra related defense and space worlds}

As of December $31^{\text {st }}, 2020$, there were 3,372 operational satellites in Earth's orbit, belonging, among others, to: USA (1,897), China (410), Russia (176) and India (63) (UCS 2021). These four countries are responsible for $75 \%$ of all operational satellites, 
with the USA accounting for $56 \%$ of them. The USA, China, Russia and India occupy the first, second, sixth and seventh positions, respectively, among the countries with the largest investments in space, having already sent unmanned spacecrafts to the Moon and Mars. One aspect that is often overlooked when evaluating the development of the different space programs in the world is their direct relationship with geopolitics and, consequently, with defense. Under the perspective of defense expenditures, the USA, China, India and Russia occupy the first, second, third and fourth positions, respectively. Two hundred and twelve of the 1,897 American satellites have military applications, whereas China, Russia and India have, respectively, 117, 103 and nine military satellites. These four nations have nuclear and anti-satellite (ASAT) weapons. In 2020, the USA spent US\$ 738 billion in defense, equivalent to $15 \%$ of its federal budget and $40 \%$ of the global defense spending (Gielow 2021). With total revenues of US\$ 165.42 billion in 2019, the Americans Lockheed Martin, Boeing, Northrop Grumman, Raytheon and General Dynamics were the five largest arms producing companies in the world. They were followed by Aviation Industry Corporation of China (AVIC), BAE Systems (United Kingdom), China Electronics Technology Group Corporation (CETC), China North Industries Group Corporation (NORINCO) and L3Harris Technologies (USA), with combined revenues of US $\$ 207.2$ billion (Statista 2020). These companies end up working on civilian space projects as well. The importance of space assets in the USA defense is such that in 2019 the United States Space Force (USSF) was created. Its budget for the 2021 fiscal year is US $\$ 15$ billion, two thirds of which to be applied to research, development, test and evaluation (DoD 2021). For comparison purpose, the total cost of Mars2020, the program that took the Perseverance rover to the Martian surface, is US\$ 2.7 billion for its 2013-2024 life cycle.

\section{Space 3.0}

From a technological point of view, the present century can be defined by the following set of factors: i) internet; ii) miniaturization of electronics, accompanied by increased reliability, processing capacity and decreased costs; iii) smartphones connected to the internet and to satellite global navigation systems; and iv) artificial intelligence. Perhaps who best defined the combined result of this set of factors was Peter Diamandis, coauthor, along with Steven Kotler, of three outstanding books (Diamandis and Kotler 2014, 2015, 2020). Diamandis created the concept “The Six Ds of Exponential Organizations," defined as: digitized, deceptive, disruptive, demonetized, dematerialized and democratized. According to Diamandis (2015):

The 6 Ds are a chain reaction of technological progression, a road map of rapid development that always leads to enormous upheaval and opportunity. (p. 8)

The so-called NewSpace, or Space 3.0, as Chris Quilty prefers, is the result of this exponential technological growth. CubeSats emerged in American universities at the end of last century. CubeSats are defined in terms of $U$ units, which may vary between 0.25 and $27 \mathrm{U}$, where $\mathrm{U}$ represents $10 \mathrm{~cm}^{3}$ modules sizes, with mass bellow $1.33 \mathrm{~kg}$. They are manufactured at low cost with reliable commercial off-the-shelf (COTS) components. The first CubeSats were launched by decommissioned ballistic missiles, or as piggyback on commercial rockets, which led to long waiting times. The ISS is also used to launch CubeSats.

What is the use of developing small, cheap satellites if there is no way to launch them at low cost? In 2002, the 30-year-old South African Elon Musk founded a company aimed at building rockets at much lower prices than those offered by the existing providers. So far, SpaceX has flown Falcon 1, Falcon 9 and Falcon Heavy, successfully. It has also, under NASA contracts, launched cargo and humans to the ISS on its Dragon spacecrafts. Falcon 9 recovers and reuses its first stage and fairing, which represent $80 \%$ of its total US\$ 62 million cost. SpaceX and its 8,000 employees are developing the reusable Starship, the most powerful rocket of all times, with which Musk intends to colonize Mars. Musk's accomplishments have motivated other groups of young entrepreneurs. Founded in 2006 by New Zealand engineer Peter Back, Rocket Lab has developed the remarkable Electron rocket, capable of putting $300 \mathrm{~kg}$ into Low Earth Orbit (LEO, bellow 2,000 km of altitude) at a cost of US\$ 7.5 million. Electron incorporated innovations in its design, including $3 \mathrm{D}$ printing and the use of high-density batteries to power its electro pumps, which feed propellant into the combustion chambers. It has initiated Electron's first stage recovery, together with its nine Rutherford engines and, recently, Peter Back has announced the development of a new and more powerful rocket named Neutron. Rocket Lab has 500 employees and, since 2018, it has launched more than 100 satellites. In 2021 the company is scheduled to launch the Cislunar 
Autonomous Positioning System Technology Operations and Navigation Experiment (CAPSTONE) CubeSat into lunar orbit, in support to the Artemis Program. On May $15^{\text {th }}$, however, an Electron rocket experienced a failure, as its second stage single Rutherford engine shut down shortly after ignition. It was Electron's third failure in 20 flights, may be just as a remind that, despite all new technologies, spaceflight is still very hard. It is worth mentioning that NewSpace, or Space 3.0, was brought about not only by advancements in technology, but also by new ways of thinking (things have to be done right, cheaper and safer, at orbital speeds, literally), financing (venture capital) and verticalization (in-house production). Moreover, NewSpace companies are largely personality-driven (Belfiore 2007; Berger 2020; Davenport 2018; Fernholz 2018; Nadis 2020).

The era of exponential growth and disruption has reached Earth's orbit and beyond. Between 2012 and 2019, 3,600 satellites were launched (Bryce Space and Technology 2020), equivalent to one third of all satellites launched since Sputnik in 1957. From those, 70\% were SmallSats, i.e., satellites under $600 \mathrm{~kg}$ mass, including 1,126 CubeSats. Initially viewed as academic experiments, CubeSats have become reliable commercial platforms. Swarm Technologies uses a constellation of $0.25 \mathrm{U}$ CubeSats, named SpaceBEE, to provide global two-way satellite communications and data relay. Spire Global uses a fleet of $3 \mathrm{U}$ CubeSats, named Lemur, to track airplanes, ships and to provide weather forecast. One of its services is the plotting of efficient ship routes to save on fuel costs. Planet provides 3-5 m resolution images through its $1003 \mathrm{U}$ CubeSats, named Dove, and 30 other SmallSats. The CubeSat Era reached deep space in 2018, when the 6 U Cubesats, MarCO-A and MarCO-B, flew by Mars and relayed data to Earth during NASA's Insight entry, descent and landing on the Red Planet.

As technology evolved and satellite size and prices went down, there has been a new surge for the launching of more than 25,000 SmallSats (Pelton and Madry 2020), 90\% of them for communications in low Earth orbit (LEO), including the following constellations: Starlink (USA), Kuiper (USA), OneWeb (United Kingdom), Telesat (Canada) and Hongyan (China). The new LEO SmallSat constellations provide a communication delay (latency) one order of magnitude smaller when compared to the 500 communication satellites in geostationary orbit (GEO). This is crucial when one considers that these SmallSats will not only connect people, but billions of devices, including autonomous cars, machines and other services still to be invented, as a result of developments in artificial intelligence (AI), internet of things (IoT) and automated identification services. But these new constellations will face fierce competition coming from $5 \mathrm{G}$ communication networks.

Presently, OneWeb constellation is operational with close to 200 SmallSats (150 kg) in LEO. Starlink intends to establish a 12,000 SmallSats $(260 \mathrm{~kg}$ ) constellation in LEO to provide global broadband internet access. So far, over 1,500 Starlink satellites are in orbit and the system is already being tested in some parts of the USA, Canada and Europe. The total estimated cost of Starlink is US\$ 10 billion and the constellation is predicted to be fully operational by the end of the decade. If everything goes well, Elon Musk will become the first human being to explore the four segments of the commercial space sector, namely: building and launching rockets; satellite manufacturing (presently, 120 satellites per month); selling of ground equipment (antenna and router); and selling of services (internet access). Today, 45\% of the operational satellites in Earth's orbit belongs to Starlink. Besides SpaceX, Musk has also created Tesla, SolarCity, The Boring Company and Neuralink. In 2020, Tesla produced 510,000 cars only, but its market value is superior to Toyota, Volkswagen, Daimler, General Motors, Ford, Honda, Hyundai, Nissan, Renault, BMW and Ferrari combined. His epoch will be marked in history books as BM and AM, meaning before and after Musk, respectively.

\section{Space debris mitigation will be key to the future of space exploration}

On January $31^{\text {st }}, 2011$, there were 975 operational satellites in Earth's orbit. Ten years later, this number has more than tripled, reaching 3,372 satellites (Table 1). A striking feature presented in Table 1 is the increase in the number of satellites operating in LEO. They increased by $464 \%$, whereas the number of monitored orbiting objects increased from 16,102 to 22,079 (CelesTrak 2021). Once the number of satellites in LEO increases by thousands in this decade, the space community concerns on the long-term sustainability of space have also increased. The United Nations Office for Outer Space Affairs (UNOOSA) is the world forum where this important subject is dealt with. 
Table 1. Evolution on the numbers of satellites and space debris during the past decade.

\begin{tabular}{|c|c|c|c|c|c|c|}
\hline Date & $\begin{array}{c}\text { Total number of } \\
\text { operational satellites }{ }^{1}\end{array}$ & LEO $^{3}$ & $\mathrm{MEO}^{4}$ & GEO $^{5}$ & Elliptical orbit ${ }^{6}$ & Monitored objects \\
\hline January $31^{\text {st }}, 2011^{1}$ & 975 & 463 & 63 & 397 & 34 & $16,102^{2}$ \\
\hline December 31st, 20201 & 3,372 & 2,612 & 139 & 562 & 59 & $22,079^{2}$ \\
\hline
\end{tabular}

1(UCS 2021); ' (CelesTrak 2021); ${ }^{3}$ LEO - low earth orbit: bellow 2,000 km; ${ }^{4} \mathrm{MEO}$ - medium earth orbit: between 2,000 and 35,786 km; ${ }^{5} \mathrm{GEO}$ - geostationary earth orbit: at $35,786 \mathrm{~km}$, on the equatorial plane; ${ }^{6}$ Elliptical: eccentricity larger than $1.4 \times 10^{-2}$ (Wright 2012).

Defunct satellites, discarded rocket stages, satellite separation subsystems, including small screws, comprise the bulk of space debris. Residual propellant left in the upper stages of satellite launch vehicles may cause their explosion, generating thousands of small pieces. Explosions of overcharged batteries generate space debris as well. It is also possible that defunct satellites break into pieces either by colliding with small space debris or by other unidentified ways. Another source of space debris are anti-satellite weapons (ASAT) tests, as the ones conducted by China and India in 2007 and 2019, respectively. The ESA (2021) estimates, through statistical models, the existence of 900 thousand fragments with sizes varying between 1 and $10 \mathrm{~cm}$, and $128 \mathrm{million}$ pieces between $1 \mathrm{~mm}$ and $1 \mathrm{~cm}$.

An eventual collision between a satellite and a piece of space debris generates thousands of smaller pieces which, by their turn, increase the probability of new collisions in a cascade phenomenon known as Kessler effect, in honor of Donald Kessler, a NASA scientist who, in 1978, raised the problem theoretically. Since then, the problem has become real, as demonstrated by the following examples:

- December 1991: A Cosmos-1934 defunct satellite was hit by a piece of debris from a Cosmos-926 satellite, both Russian.

- July 1996: The French military satellite, Cerise, launched in 1995, was hit by a fragment of the Ariane 1 rocket, which exploded 10 years earlier.

- January 2005: An upper stage of an American rocket launched in 1974 was hit by a fragment of a Chinese CZ-4 rocket, whose third stage had exploded in 2000.

- February 2009: An operational Iridium-33 communication satellite collided with Kosmos-2251, a defunct Russian military communications satellite. The collision generated thousands of fragments.

- September 2019: The ESA had to move its Aeolus Earth observation satellite to avoid collision with Starlink-44 satellite (Foust 2019).

- March 2021: The USSF's reported that the American NOAA-17 polar-orbiting weather satellite, decommissioned in 2013, broke into dozens of pieces larger than $10 \mathrm{~cm}$, with no indication it happened as a result of a space debris collision.

- March 2021: The Yunhai 1-02 Chinese meteorological satellite, launched in September 2019, broke into 21 pieces (Foust 2021a).

- April 2021: A close call involving OneWeb-0178 and Starlink-1546 satellites had to be dealt with by maneuvering OneWeb-0178 (Foust 2021b).

- Between 1999 and 2020 the ISS had to be maneuvered 28 times to avoid collision with space debris (Foust 2020).

- May 2021: After launching the first module of the Chinese Space Station, Tianhe, the empty first stage of Long March 5B rocket fell into the Indian Ocean causing concern in the international community (Jones 2021).

Such examples have made some government officials express their concerns publicly. In September 2020, NASA's Administrator Jim Bridenstine tweeted (Foust 2020), as shown in Fig. 1: 


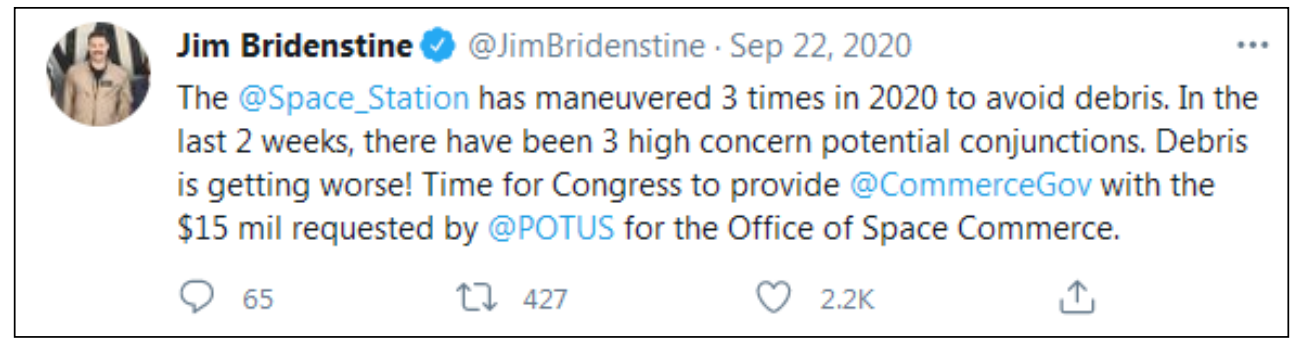

Figure 1. Jim Bridenstine tweet.

As expected, the military have also expressed their concerns. General David Thompson, vice chief of space operations of the USSF said:

Obviously, the Department of Defense wants a voice in that, in terms of what it means to us. We'll have to play our role, whatever it needs to be, but it's definitely time for an agency responsible for regulation and regulatory rules and norms to take a more active role, for both the United States but also in dealing with international bodies. (Erwin 2021)

In a 2021 report, NASA’s Office of Inspector General (OIG) stated:

Multiple studies have found that the growth of debris in LEO can be slowed by ensuring that at least 90 percent of all spacecraft are removed from orbit within 25 years of the end of their mission, and at least five defunct spacecraft (that will not deorbit on their own) are actively removed from orbit every year. (NASA 2021b, p. 3)

With regard to the Long March 5B event, the White House press secretary, Jen Psaki, said:

The United States is committed to addressing the risks of growing congestion due to space debris and growing activity in space and we want to work with the international community to promote leadership and responsible space behaviors. (Reuters 2021)

As it becomes clear that mitigation policies will not be sufficient to address the problem, startups and governmental bodies are working on ways of not only monitoring space debris, but also deorbiting them. LeoLabs (2021) uses a network of radars and algorithms to track orbiting objects. Its S-band phased-array radars are capable of tracking $2 \mathrm{~cm}$ space debris. ClearSpace, a Swissbased startup, was selected by ESA, among 11 other competitors, to develop a spacecraft capable of using robotic arms to capture space debris. The mission, ClearSpace-1, is scheduled to 2025, when it will try to capture a $100 \mathrm{~kg}$ Vega's rocket secondary payload adapter, left in orbit in 2013. After capturing its target object, ClearSpace-1 will deorbit and reenter into Earth's atmosphere, when both will burn up. The ESA is paying ClearSpace $€ 86$ million, which will not cover ClearSpace-1 total development costs. The additional funds will come from private investors, who believe to have a business case for future space debris removal (Mathewson 2021).

In March 2021, a Soyuz rocket launched the End-of-Life Services by Astroscale demonstration (ELSA-d) mission (Wade 2021). The payloads are a $17 \mathrm{~kg}$ target satellite, which will mock a space debris and a $180 \mathrm{~kg}$ chaser satellite. They were launched attached to each other through a magnetic docking plate. Once in orbit, at $500 \mathrm{~km}$, they will execute three different separation and capturing tests, the last of which, to take place later this year, will induce reentry of the chaser-target satellites into the Earth's atmosphere, where they will burn up. The chaser satellite was built by Astroscale, a Japanese startup which got US\$ 191 million from private investors. The British Surrey Satellite Technology Ltd (SSTL) was responsible for the target satellite. If everything goes well, Astroscale and SSTL intend to provide capturing and deorbiting services to defunct satellites, which will only work for satellites equipped with their magnetic docking system, as it is the case of the OneWeb constellation satellites (Clark 2021). 


\section{The "gold rush" in space}

The commercialization of space, nonetheless, is not restricted do mega satellite constellations operating in LEO. The Space 3.0 environment contemplates a plethora of bold ideas. One of them, the CisLunar-1000, was presented in 2015 by United Launch Alliance (ULA). It foresees the establishment of a self-sustained space infrastructure capable of keeping 1,000 humans permanently working in space by 2045 (Pyle 2019). By then, according to predictions by ULA, the space economy will reach US $\$ 2.7$ trillion per year. The CisLunar-1000 concept involves the creation of a space ecosystem which includes: the production of rocket propellant; the establishment of orbiting fuel depots; space hotels; solar power satellites (to provide energy to operate in space); water, oxygen and food production; fleets of reusable rockets to allow for the transportation of people and cargo between different locations; robots to produce in situ resources through mining; and fabrication of 3D printed structures using materials available in space. The idea behind this concept is that it is cheaper to produce in space all needed supplies through in situ resource utilization (ISRU), instead of producing them on Earth and transferring them to space through Earth's steep gravity well. According to Pyle (2019):

The ultimate goal of space infrastructure is the ongoing availability of the assets and resources needed to live and work in space, derived from space-based sources - water and building materials from the moon and asteroids, for example. (p. 205)

Governments will play an important role in establishing the Cislunar-1000 proposal, through public-private partnerships. In 2019, for example, NASA awarded the company Made in Space, a US\$ 73.7 million contract to fly the On-Orbit Servicing, Assembly and Manufacturing (OSAM-2) spacecraft, capable of building and assembling complex systems in space through additive manufacturing. The OSAM- 2 is scheduled to be launched no earlier than 2022 by an Electron rocket. Once in orbit, OSAM- 2 will 3D print two $10 \mathrm{~m}$ beams on each side of the spacecraft. The beams will work as solar arrays. In 2014, Made in Space flew a 3D printer to the ISS, where several components were successfully produced under microgravity conditions. There are also publicprivate initiatives to reduce the cost of sending people and cargo to space. NASA's Commercial Orbital Transportation Services (COTS) allowed for the development of Falcon 9 for US\$ 400 million. A study conducted by NASA, using NASA/Air Force Costing Methodology computer modeling, revealed that Falcon 9 would have cost US $\$ 4$ billion if done under traditional NASA practices. Under COTS, NASA did not pay for Falcon 9 total development cost, as SpaceX had to invest its own money under the expectation it will sell Falcon 9 flights to other customers. The same model was successfully used by NASA for hiring SpaceX and Orbital ATK to deliver cargo to the ISS through the Commercial Resupply Services (CRS) Program. In 2014, under its Commercial Crew Program, NASA hired SpaceX and Boeing to develop spacecrafts to ferry astronauts to the ISS. A study conducted by NASA office of inspector general (OIG) revealed that the space agency will pay US\$ 90 million/seat to fly astronauts onboard Boeing's CST100 Starliner, as compared to US\$ 55 million/seat it pays to fly them onboard Crew Dragon (Wall 2020). As of May 2021, SpaceX has flown three missions to the ISS and Boeing none. NASA is also applying similar procedure to hire the human landing system (HLS) to carry astronauts to and from Moon's surface. SpaceX, Blue Origin and Dynetics are competing for the bid, which now is in the hands of the Government Accountability Office (GAO) and Congress, due to a controversial decision made by NASA, on April $16^{\text {th }}$, to award US $\$ 2.89$ billion to SpaceX only. It was expected that NASA selected two companies to develop the HLS, but the space agency argued it made the best and cheapest choice given the limited funds provided by the Congress. Blue Origin and Dynetics did not agree with NASA's decision and the bidding process turned into a legal and political battle.

Besides disruptive technologies, management style, internal culture, budget constraints and special interest groups, politics has played an important role on NASA's decision-making process, affecting its accomplishments and costs. Although not related to space directly, Micklethwait and Wooldridge (2020) presented an outstanding discussion on how western governments, the USA and UK included, were not capable of adapting themselves to the disruptive changes which occurred in the past three decades.

With regards to the future of human space flight, two lobby groups may be identified, one which defends a direct trip to Mars (Zubrin 2011; 2013) and other which thinks the Moon shall be the next destiny (Spudis 2016). Aldrin and David (2013) suggest the creation of the International Lunar Development Corporation (ILDC) to explore the Moon with rovers operated from Earth. The resulting knowledge would then be applied to Mars, where rovers would be operated by humans from Phobos, one of the two moons of Mars. All groups agree that, next time, the mission should not be to plant a flag only, but to establish human settlements 
with strategic, scientific and economic purposes. They also think that exploration of the Moon, Mars, asteroids, and even comets will be profitable to the private groups involved. Their rationale is to guarantee the survival of the human civilization against natural (asteroid impact or huge volcanic eruptions) or human made disasters (atomic war or climate change). But since the lifeboat will not be for all, that seems a difficult rationale to sell, as most of the human civilization may end up living in a world as depicted on the 2013 dystopic movie Elysium. Using similar arguments, Elon Musk intends to establish a one million people colony on Mars during his lifetime. Jeff Bezos wants to contribute towards the realization of his childhood dream of establishing human colonies in space, as imagined by his former Princeton professor Gerard O’Neill (1977). The fact that this discussion is led by two billionaires, instead of governmental space agencies, is an indication of how much the space world has changed in the past 20 years, but things are not that simple.

Establishing a Moon outpost is less expensive, risky and difficult than on Mars, where less than half of the 49 unmanned missions were successful. While a one-way trip to the Moon lasts three days on a 400 thousand km journey, it takes 200 days, and more than 400 million $\mathrm{km}$ to get to the red planet. The two-way Earth-Moon communication delay is about $3 \mathrm{~s}$, almost "real time" when compared to the 6 to 44 min Earth-Mars-Earth connection time. The longest Apollo mission lasted 12 days, whereas a typical manned Mars mission will take 900 days. The Apollo spacecrafts carried the propellant necessary for the return trip, in addition to food, water and oxygen to breath. In the Martian case, these resources will have to be produced locally by automated machines to be sent in advance, and, if the astronauts are to have a survival chance, they will have to land close to these utilities. That is why SpaceX Starship spacecraft uses methane as fuel, instead hydrogen or kerosene. The idea is to produce methane and oxygen out of the carbon dioxide and water available on Mars. In April, Perseverance MOXIE experiment produced $5 \mathrm{~g}$ of oxygen out of the carbon dioxide present in the Martian atmosphere. It is sufficient to keep a human alive for 10 min. Keeping people in a confined space for one week is one thing, but keeping them confined during a six months one-way journey to Mars is much more challenging. The deleterious psychological and physical conditions of the voyagers upon arrival will limit their ability to operate on Mars. Not to mention the risks imposed to human health by cosmic radiation during the trip itself and on Mars surface. Ten years ago, the Dutch project Mars One (Kraft et al. 2016) tried to simplify the scientific facts and stick with the fiction. Somehow, it mimicked Julio Verne's novel From the Earth to the Moon, published in 1865. Beginning with 4,227 volunteers, Mars One would, after several selection rounds, choose 24 volunteers who would be sent to Mars in six different groups on a one-way trip, at an estimated cost of US\$ 6 billion. The Mars One initiative drew a lot of media attention, but in 2019 it was declared bankrupt.

Moon's settlement will require hundreds of billion dollars, whereas Mars's settlement will cost many trillions. In a recent interview to Peter Diamandis to announce the US\$ 100 million XPRIZE for Carbon Removal (XPRIZE 2021), Elon Musk said "honestly, a bunch of people will probably die in the beginning". Simberg (2014) dedicated a book on the safety issue, which was also dealt with by Zubrin (2013). Their conclusion is: if we are not prepared to face the risks, we would better not even try, as deaths will be certain. At this point, it is worth recalling a cover story brought by The Economist (2011), entitled The end of the Space Age. It stated:

Unless life turns up on Mars, or somewhere even more unexpected, public interest in the whole thing is likely to wane. And it is the public that pays for it all.

Therefore, before any decision is made, it will be necessary to develop its rationale and to define who will finance it.

The reasoning for the Apollo Program was the Cold War between the USA and the former USSR. In 1970, China became the fifth nation in the world to put a satellite, China 1, into Earth's Orbit. In 2003, it had its first taikonaut in orbit. Four years later the Chinese have placed the spacecraft Chang'e 1 to orbit the Moon, followed by Chang'e2, in 2010. In 2013, China landed Chang' 3 on the Moon. Since 2015, China overtook Russia in numbers of operational satellites orbiting the Earth. In 2019, Change 4 became the first spacecraft ever to land on the far side of the Moon. In December 2020, Chang' 5 brought $1.7 \mathrm{~kg}$ of lunar rocks back to Earth. On June $23^{\text {rd }}, 2020$, China completed its global satellite navigation system, Beidou. It was on April $29^{\text {th }}, 2021$ that a Long March $5 B$ placed the first 22,600 kg module of the Tianhe Chinese Space Station into Earth's orbit. On May 15 ${ }^{\text {th }} 2021$, China became the second nation in the world to successfully land a rover on the red planet, Zhurong. In March, China and Russia announced they were developing an International Lunar Research Station (ILRS), comprised of a set of experimental research facilities on and around the Moon. They 
made it clear that other nations are welcome to join in, but, since 2011 (Wolf Amendment), NASA is forbidden to collaborate with China, unless authorized by the Federal Bureau of Investigation (FBI) and the US Congress. Meanwhile, Australia, Canada, Italy, Japan, Luxembourg, New Zealand, South Korea, Ukraine, United Arab Emirates and United Kingdom, have signed Artemis Accords to participate in the American-led program. In this geopolitical competition, India will become an important player, should that country decide to join Russia and China on the ILRS Program. Will that competition open the door for a new space race?

\section{CONCLUSION}

In November 1961, Carl Sagan and other 10 scientists got together in Green Bank, West Virginia, USA, to discuss the existence of other intelligent communicative civilizations in the Milky Way galaxy. To direct the discussions, Frank Drake proposed the now famous Drake Equation, composed of seven terms, the last of which related to the amount of time such intelligent civilization would survive before disappearing, either by a natural accident (e.g., asteroid impact) or by its own action (e.g., nuclear war). They concluded there could exist between twenty and fifty million intelligent communicative civilizations, but. sixty years later, no extraterrestrial civilization has shown up.

In December 1968, Apollo 8 astronauts circumnavigated the Moon for the first time. They made the most important discovery of the Space Age ever, synthesized by the astronaut William Anders as shown in Fig. 2:

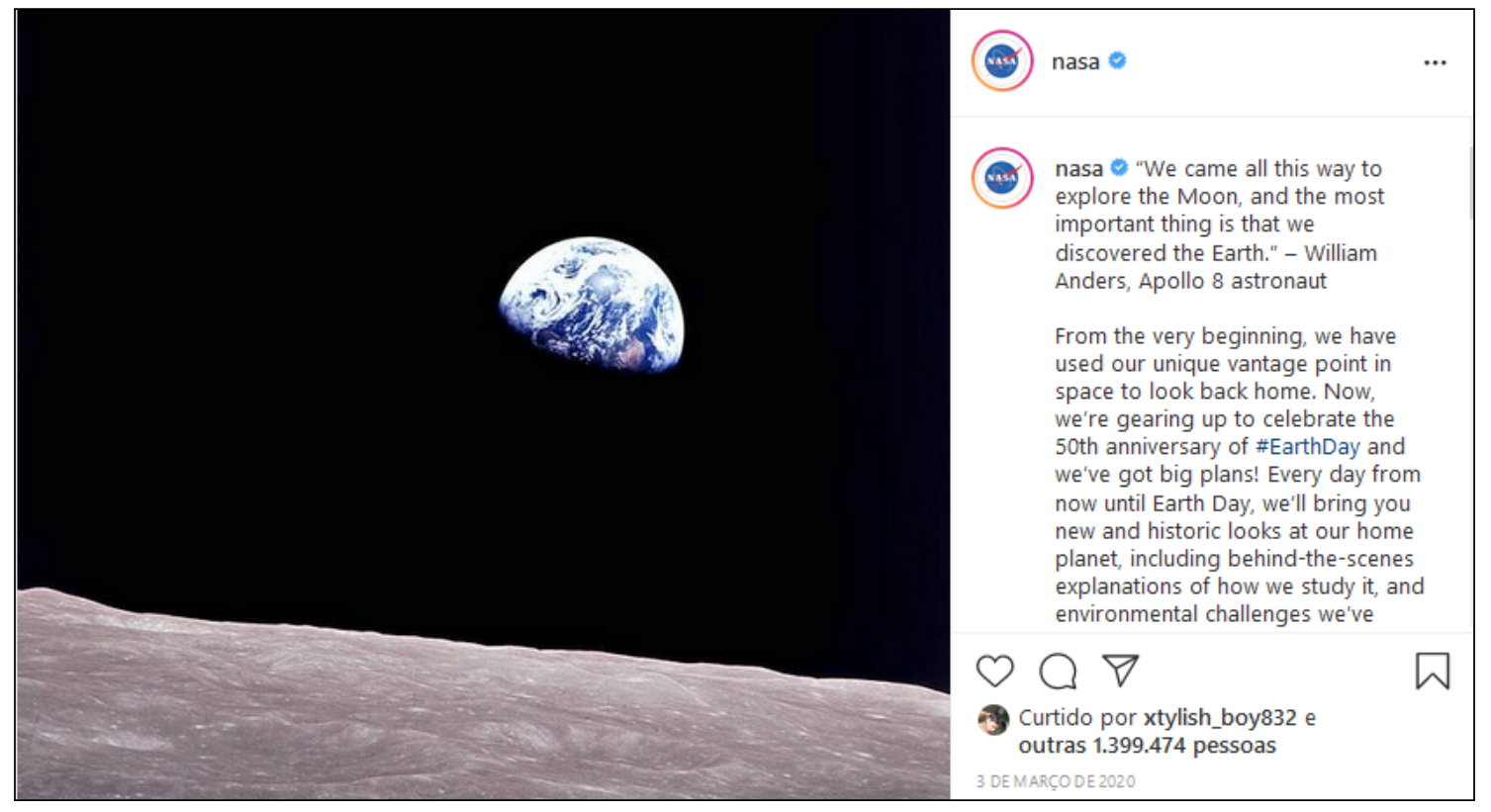

https://www.instagram.com/p/B9R1ZxWFBwX/

Figure 2. Earth rise viewed by Apollo 8 astronauts on December $24^{\text {th }} 1968$.

The Space Age has brought uncountable benefits to the human civilization, but space assets have also provided unquestionable evidence that its development model is not sustainable and a great disruption is under way (Gilding 2011). The World Economic Forum (2021) presented a survey on the global risks perceptions. In terms of probability, extreme weather, climate action failure, human environmental damage, infectious diseases and biodiversity loss occupied the top five positions, whereas in terms of impact infectious diseases, climate action failure, weapons of mass destruction, biodiversity loss and natural resources crises were the top five. The resulting risk matrix left no doubt: if the human race is to survive, it will have to change its competitive mindset to a cooperative one. Impossible? It better not be, as it does not have any better place to go, and time is running out. 


\section{DATA AVAILABILITY STATEMENT}

Not applicable.

\section{FUNDING}

Not applicable.

\section{ACKNOWLEDGEMENTS}

I acknowledge Dr. Alison Moraes, Associate Editor of the Journal of Aerospace Technology and Management, for the invitation and incentive to write this article.

\section{REFERENCES}

[DoD] Department of Defense (2021) Defense Budget Overview: Irreversible Implementation of the National Defense Strategy. United States Department of Defense Fiscal Year 2021 Budget Request. Office of the Under Secretary of Defense (Comptroller)/Chief Financial Officer. [accessed May 3 2021]. https://comptroller.defense.gov/Portals/45/Documents/ defbudget/fy2021/fy2021_Budget_Request_Overview_Book.pdf

[ESA] The European Space Agency (2021) Satellites vs Debris. ESA. [accessed May 17 2021]. https://www.esa.int/ESA_ Multimedia/Images/2021/02/Satellites_vs_Debris

[NASA] National Aeronautics and Space Administration (2021a) Nasa Exoplanet Archive: A Service of NASA Exoplanet Science Institute. [accessed May 3 2021]. https://exoplanetarchive.ipac.caltech.edu/

[NASA] National Aeronautics and Space Administration (2021b) NASA's Efforts to Mitigate the Risks Posed by Orbital Debris [Report nº. IG-21-011]. [accessed May 15 2021]. https://oig.nasa.gov/docs/IG-21-011.pdf

[SIA] Satellite Industry Association (2020) State of the Satellite Industry Report. [accessed May 3 2021]. https://sia.org/newsresources/state-of-the-satellite-industry-report/

[UCS] Union of Concerned Scientists (2021) Satellite Database: In-depth details on the 3,372 satellites currently orbiting Earth, including their country of origin, purpose, and other operational details. [accessed May 3 2021]. https://www.ucsusa. org/resources/satellite-database

Aldrin B, David L (2013). Mission to Mars: My Vision for Space Exploration. Washington: National Geographic.

Belfiore M (2007) Rocketeers: How a visionary band of business leaders, engineers and pilots is boldly privatizing space. Washington: Smithsonian Books.

Berger E (2021) Liftoff: Elon Musk and the desperate early days that launched SpaceX. Glasgow: William Collins.

Bryce Space and Technology (2020) SmallSats by the Numbers. [accessed May 3 2021]. https://brycetech.com/reports/reportdocuments/Bryce_Smallsats_2020.pdf

CelesTrak (2021) SATCAT Boxscore. [accessed May 16 2021]. https://celestrak.com/satcat/boxscore.php

Clark S (2021) Privately-funded mission takes off to begin space debris cleanup trials. Spaceflight Now. [accessed May 17 2021]. https://spaceflightnow.com/2021/03/22/privately-funded-mission-takes-off-to-begin-space-debris-cleanup-trials/ 
Davenport C (2018) The Space Barons: Elon Musk, Jeff Bezos, and the Quest to Colonize the Cosmos. New York: PublicAffairs.

Diamandis PH, Kotler S (2014) Abundance: The Future Is Better Than You Think. New York: Simon \& Schuster.

Diamandis PH, Kotler S (2015) Bold: How to Go Big, Create Wealth and Impact the World. New York: Simon \& Schuster.

Diamandis PH, Kotler S (2020) The Future Is Faster Than You Think: How Converging Technologies Are Transforming Business, Industries, and Our Lives. New York: Simon \& Schuster.

Erwin S (2021) Space Force sees need for civilian agency to manage congestion. Space News. [accessed May 3 2021]. https:// spacenews.com/space-force-sees-need-for-civilian-agency-to-manage-congestion/

Fernholz T (2018) Rocket Billionaires: Elon Musk, Jeff Bezos, and the New Space Race. Boston: Houghton Mifflin Harcourt.

Foust J (2019) Better coordination needed among operators to avoid potential collisions. Space News. [accessed May 32021 ]. https://spacenews.com/better-coordination-needed-among-operators-to-avoid-potential-collisions/

Foust J (2020) Space station maneuvers to avoid debris. Space News. [accessed May 3 2021]. https://spacenews.com/spacestation-maneuvers-to-avoid-debris/

Foust J (2021a) The growing case for active debris removal. The Space Review. Space News. [accessed May 15 2021]. https:// www.thespacereview.com/article/4150/1

Foust J (2021b) SpaceX and OneWeb spar over satellite close approach. Space News. [accessed May 3 2021]. https://spacenews. com/spacex-and-oneweb-spar-over-satellite-close-approach/

Gielow I (2021) Gasto militar global equivale a 1 ano de Bolsa Família por dia. [accessed May 3 2021]. Folha de S. Paulo. UOL. https://www1.folha.uol.com.br/mundo/2021/02/gasto-militar-global-equivale-a-um-bolsa-familia-por-dia-em-2020.shtml

Gilding P (2011) The Great Disruption: How the Climate Crisis will Transform the Global Economy. London: Bloomsbury.

Jones A (2021) Long March 5B falls into Indian Ocean after world follows rocket reentry. Space News. [accessed May 17 2021]. https://spacenews.com/long-march-5b-falls-into-indian-ocean-after-world-follows-rocket-reentry/

Kraft N, Kass JR, Kass R, Hooft GT (2016). Mars One, Humanity’s Next Great Adventure: Inside the First Human Settlement on Mars. Dallas: BenBella Books.

LeoLabs (2021): The Mapping Platform for Space. LeoLabs. [accessed May 3 2021]. https://www.leolabs.space/

Mathewson S (2021) ESA partners with startup to launch first debris removal mission in 2025. SPACE.com. [accessed May 17 2021]. https://www.space.com/esa-startup-clearspace-debris-removal-2025

Micklethwait J, Wooldridge A (2020) The Wake-Up Call: Why the pandemic has exposed the weakness of the West - and how to fix it. London: Short Books.

Nadis F (2020) Star Settlers: The Billionaires, Geniuses, and Crazed Visionaries Out to Conquer the Universe. New York: Pegasus Books.

O’Neill, GK (1977) The High Frontier: Human Colonies in Space. New York: William Morrow and Company.

Pelton JN, Madry S (2020) Handbook of Small Satellites: Technology, Design, Manufacture, Applications, Economics and Regulation. New York: Springer. https://doi.org/10.1007/978-3-030-36308-6

Pyle R (2019) Space 2.0: How private spaceflight, a resurgent NASA, and international partners are creating a new space age. Dallas: Ben Bella Books.

Simberg R (2014) Safe is not an option: Overcoming the futile obsession with getting everyone back alive that is killing our expansion into space. Interglobal Media LLC. 
Reuters (2021) U.S. tracking China rocket debris - White House [accessed May 12 2021]. https://www.reuters.com/world/us/ us-tracking-china-rocket-debris-white-house-2021-05-05/

Spudis PD (2016) The Value of the Moon: How to Explore, Live, and Prosper in Space Using the Moon's Resources. Washington: Smithsonian Books.

Statista (2020) Largest arms-producing and military services companies worldwide in 2019, by arms sales in million U.S dollars). [accessed May 12 2021]. https://www.statista.com/statistics/267160/sales-of-the-worlds-largest-arms-producingand-military-services-companies/

Sweeting MN (2018) Modern Small Satellites - Changing the Economics of Space. Proc IEEE 106(3):343-361. https://doi. org/10.1109/JPROC.2018.2806218

The Economist (2011) The end of the Space Age. [accessed May 5 2021]. https://www.economist.com/leaders/2011/06/30/ the-end-of-the-space-age

The Planetary Society (2021) How much did the Apollo program cost? [accessed May 3 2021]. https://www.planetary.org/ space-policy/cost-of-apollo

von Braun W (1953) The Mars Project. Champaign: University of Illinois.

Wade A (2021) Astroscale launches space debris removal mission. The Engineer. [accessed May 15 2021]. https://www. theengineer.co.uk/astroscale-launches-space-debris-removal-mission/

Wall M (2020) Here's How Much NASA Is Paying Per Seat on SpaceX's Crew Dragon \& Boeing's Starliner. [accessed May 3 2021]. https://www.space.com/spacex-boeing-commercial-crew-seat-prices.html

World Economic Forum (2021) The Global Risks Report 2021: Insight Report. [accessed May 3 2021]. http://www3.weforum. org/docs/WEF_The_Global_Risks_Report_2021.pdf

Wright D (2012) All Things Nuclear: North Korea’s Satellite. Union Concerned Scientists. [accessed May 19 2021]. https:// allthingsnuclear.org/dwright/north-koreas-satellite/

XPRIZE (2021) \$100M Prize for Carbon Removal. [accessed May 12 2021]. https://www.xprize.org/prizes/elonmusk

Zubrin R (2011) Case for Mars: The Plan to Settle the Red Planet and Why We Must. New York: Free Press.

Zubrin R (2013) Mars Direct: Space Exploration, the Red Planet, and the Human Future. New York: TarcherPerigee. 